Check for updates

Cite this: Phys. Chem. Chem. Phys., 2019, 21, 5614

Received 19th December 2018, Accepted 13th February 2019

DOI: $10.1039 / \mathrm{c} 8 \mathrm{cp} 07751 \mathrm{~g}$

rsc.li/pccp

\title{
Modeling of type IV and V sigmoidal adsorption isotherms $\dagger$
}

\author{
Christoph Buttersack iD
}

\begin{abstract}
Based on the biochemical theory of multiple ligand-receptor complexes (Klotz (1946)) a sigmoidal proceeding adsorption isotherm is derived. The special case of an arbitrarily large number of equal interaction sites and a separate one yields an equation which corresponds to the $\zeta$-isotherm, disparately derived by Ward et al. (2007) for surface tension of solid-fluid interfaces. From the mathematical point of view it is analogous to the BET-isotherm for a limited number of adsorption layers (1938). It is shown that the isotherm maps type IV and $V$ isotherms. The isotherm is compared with others including the type IV isotherm of Do and Do (2009). The present isotherm is unified in contrast to existing hybrid models. It is successfully applied to numerous literature data concerning the adsorption of water on

microporous carbon and aluminophosphate molecular sieves.
\end{abstract}

\section{Introduction}

A sigmoidal course of an adsorption isotherm is caused by lateral attracting interactions between the adsorbed species. It is identical with type $\mathrm{V}$ of the IUPAC classification and is part of type IV and VI isotherms. ${ }^{1}$ An example for such isotherms the capillary condensation during the pore filling of micropores. It covers the adsorption of water on hydrophobic microporous solids such as aluminum phosphate (ALPO), silicon aluminum phosphate (SAPO) and similar zeolite analog materials, ${ }^{2-6}$ metal organic frameworks (MOFs) ${ }^{7}$ and activated carbon. ${ }^{8,9}$ At last the capillary condensation in mesoporous materials has to be mentioned. Here, type IV isotherms are mostly observed during the adsorption not only for $\mathrm{N}_{2}$ and $\mathrm{Ar}^{10}$ but also for water and numerous organics. ${ }^{11-18}$ An s-shaped isotherm can also occur when capillary condensation is improbable. Aqueous phase adsorption is sometimes attended by the formation of dimers, trimers and so on. Examples are protein-ligand interactions ${ }^{19,20}$ while examples of quite other systems with carbon ${ }^{21}$ and with inorganic sorbents ${ }^{22-24}$ are seldom.

All these phenomena were subject of modeling by an appropriate isotherm. The probable most simplest equation for describing cooperative effects has been proposed by Dubinin and Serpinski. ${ }^{25}$ Deviating from Langmuir's equation only by a sign, the degree of coverage is

$$
\theta=\frac{K x}{1-K x}
$$

Institute for Non-Classical Chemistry at Leipzig University, Permoser Str. 15, 04318 Leipzig, Germany. E-mail: christoph.buttersack@uni-leipzig.de $\dagger$ Electronic supplementary information (ESI) available. See DOI: 10.1039/ c8cp07751g with $K$ being the binding constant on already adsorbed molecules. With increasing concentration or partial pressure $x$ in the bulk phase, clusters are formed with increasing size. By this way $\theta$ approximates infinite, and the usual phenomenon of saturation and s-shape is missing. That equation is now mainly used in chromatography for describing simple type III isotherms and named there Anti-Langmuir equation. ${ }^{26,27}$

To achieve an extension of the Langmuir concept to a sigmoidal isotherm, Malakhov and Volkhov ${ }^{28}$ have developed their cooperative multimodal sorption theory. After some simplification the Langmuir type equation

$$
\theta=\frac{K x}{w^{2}-K x}
$$

with the interaction parameter $w$ being a function of $x$ according to

$$
w=\frac{1}{2}\left(1-K_{1} x+\sqrt{\left(1-K_{1} x\right)^{2}+4 K x}\right)
$$

and $K_{1}>K$ as additional parameter is obtained. ${ }^{29}$ Another but similar approach has been presented by Chakraborty. ${ }^{30}$

However, it is principally easier to define the mutual interaction between the adsorbed species as a function of the degree of coverage $\theta$. This is done in the equation of Fowler and Guggenheim $^{31}$

$$
K x=\frac{\theta}{1-\theta} \exp \left\{\frac{-2 \omega \theta}{R T}\right\}
$$

It can be conceived as a Langmuir isotherm which is extended by an exponential term with an exponent proportional to the degree of coverage $\theta$ and a lateral interaction energy $\omega$. 
For non-localized adsorption systems eqn (4) needs to be extended by an additional term accounting for the adsorbate mobility. In the resulting equation of Hill-de Boer ${ }^{31}$

$$
K x=\frac{\theta}{1-\theta} \exp \left\{\frac{\theta}{1-\theta}\right\} \exp \left\{\frac{-z \omega \theta}{R T}\right\}
$$

$z$ is the coordination number (usually taken as 4 or 6 depending on the packing of the molecules), and $\omega$ the lateral interaction energy again. A further equation for sigmoidal isotherms, also based on non-localized sorption, but with another interaction term has been derived and applied to water sorption isotherms on carbon by Talu and Meunier. ${ }^{32}$

The isotherms presented so far are formally related to monolayer sorption. The fractional uptake $\theta$ is ranging between zero and unity. The approaches presented in the following rely on the multisite or multilayer concept. The fractional uptake is here also considered to be the amount of adsorbed species per site or per monolayer fraction so that $\theta$ can comprise all positive numbers.

As an example for multisite sorption the general isotherm for the formation of adsorbate clusters has to be presented here. When $\mathrm{S}$ is the a primary binding site on the adsorbent $\mathrm{A}$, the cluster formation is described by

$$
\mathrm{S}+\mathrm{A} \leftrightarrow \mathrm{SA} ; \quad \mathrm{SA}+\mathrm{A} \leftrightarrow \mathrm{SA}_{2} ; \quad \mathrm{SA}_{2}+\mathrm{A} \leftrightarrow \mathrm{SA}_{3}
$$

and so on. Based on this a successive thermodynamical equilibrium a $m$-fold clustering with the association constants $K_{i}$ is established according to

$$
\theta=\frac{K_{1} x+2 K_{1} K_{2} x^{2}+3 K_{1} K_{2} K_{3} x^{3}+\cdots+m\left(K_{1} K_{2} K_{3} \ldots K_{i}\right) x^{m}}{1+K_{1} x+K_{1} K_{2} x^{2}+K_{1} K_{2} K_{3} x^{3}+\cdots+\left(K_{1} K_{2} K_{3} \ldots K_{i}\right) x^{m}}
$$

That equation has originally been presented by Klotz ${ }^{19,20}$ for the multiple binding of ligands on proteins. Provided that an accurately measured experimental adsorption isotherm exists, the values of $K_{i}$ signifying the formation of the monomer, dimer, trimer etc. can be obtained by non-linear regression. Values up to $m=10$ have been determined. ${ }^{33}$

In most cases the experimental accuracy would be not so high, and in case of water clustering on apolar micropores it may reasonable to assume, beside the primary association, all following to have the same value. Then eqn (6) reduces to

$$
\theta=\frac{\sum_{i=1}^{m} i K_{1} K^{i-1} x^{i}}{1+\sum_{i=1}^{m} K_{1} K^{i-1} x^{i}}
$$

This is a function with only 3 adjustable parameters which are $K_{1}, K$ and $m$. The equation is part of Do and Do's model of water sorption in activated carbon. First presented with $m=6^{34}$ it was later extended to $m$ as free parameter resulting from the fitting procedure. ${ }^{35}$ Eqn (7) has been used to describe the formation of water clusters around the primary adsorption sites. However, Do and Do assumed a limited clustering around functional sites at the carbon surface and subsequent formation of super-clusters around the primary clusters. The formation of these super-clusters, which are the reason of the sigmoidal course of the isotherm, was not described by eqn (7) but by another additional term..$^{34,35}$ Do and Do's model is further discussed later on.

Eqn (7) with $K=1$ is also important for the derivation of the BET model. For a limited number of $n$ layers the result is ${ }^{36}$

$$
\theta=\frac{C x\left\{1-(1+n) x^{n}+n x^{n+1}\right\}}{(1-x)\left\{1+(C-1) x-C x^{n+1}\right\}}
$$

Brunauer, Emmett and Teller did not recognize that their equation can display a sigmoidal course. This is not surprising because that behavior can occur only at $x>1$ which is beyond the limit of partial pressure. However, in 2007 the derivation of the so-called $\zeta$-isotherm was published. ${ }^{37}$ The starting point was Anderson's modified BET equation which was found to be very successful in fitting of numerous experimental type II isotherms also at high partial pressure. It is mainly known in the literature as GAB-isotherm. ${ }^{38}$ Anderson has related the common BET isotherm not to the partial pressure but to a lower apparent pressure given by

$$
z=K_{\mathrm{a}} x
$$

with $K_{\mathrm{a}}$ being an adjustable parameter experimentally ranging from 0.6 to $0.8 .^{31,39}$ The deviation from classical BET is best explained by the idea that the properties of the layers above the first are constant but not necessarily the same as those in the bulk liquid. ${ }^{40}$ The $\zeta$-isotherm contains the $C$-parameter of the common multilayer-BET isotherm and the modified partial pressure $z$

$$
\theta=\frac{C z\left\{1-(1+\zeta) z^{\zeta}+\zeta z^{\zeta+1}\right\}}{(1-z)\left\{1+(C-1) z-C z^{\zeta+1}\right\}}
$$

The isotherm can display a sigmoidal course for $z>1^{41}$

A general multilayer isotherm, which maps also the course of type IV and V, has been published by Brunauer et al. ${ }^{42}$ after their pioneering work in $1938^{39}$ as an extension of the BET equation by assuming that increasing the number of multilayers $n$ is coupled with an enhanced probability to be adsorbed on both sides of the capillary walls. The following equation, also known as BDDT isotherm, has been derived:

$$
\theta=\frac{C x}{1-x} \frac{1+(n g / 2-n)^{n-1}-(n g-n+1) x^{n}+(n g / 2) x^{n+1}}{1+(C-1) x+(C g / 2-C) x^{n}-(C g / 2) x^{n+1}}
$$

For $g>1$ and $C<1$ type $\mathrm{V}$ isotherms result, type IV isotherms are obtained for $g>1$ and $C>1$. However, because of its complicated nature this equation was only seldom applied to isotherm analysis. ${ }^{38}$

Beside these theoretically founded isotherms numerous empirical or half-empirical equations exist. ${ }^{31}$ One of them is the Sips isotherm ${ }^{31}$

$$
\theta=\frac{(b x)^{s}}{1+(b x)^{s}}
$$

being sigmoidal for $s>1$. Under the theoretical view, it is regarded to fail because the slope at $x=0$ is zero. Hence the Henry condition is not fulfilled. However, in case of water sorption on 
hydrophobic surfaces the Sips equation can be derived based on a thermodynamical equilibrium of water clusters and thus can have a theoretical background. ${ }^{43,44}$ Beside the questions attending its derivation it has found numerous application. Especially, the analyses of type IV isotherms by an additive superposition of Langmuir and Sips have to be reported here. ${ }^{15-18,45}$

The Dubinin equations

$$
\theta=\exp \left\{-\left(\frac{R T \ln (1 / x)}{E}\right)^{n}\right\}
$$

scaled against the characteristic energy $E$ have a principally sigmoidal course. These types of equations are only empirical because the underlying Weibull energy distribution has no theoretical foundation ${ }^{46}$ and a Henry region at low degrees of coverage is missing. The Dubinin-Radushkevich equation $(n=2)$ is routinely employed for the extrapolation of micropore filling ${ }^{47}$ where the point of inflection, mostly situated in the low pressure region, has no impact in the practice. Only the Dubinin-Astakhov variant with $n$ as adjustable parameter has been used for curve fitting of s-shaped isotherms. ${ }^{2,17,18}$

The systems considered so far are regarded to be mainly homogeneous. However, a sigmoidal isotherm can also be the result of a heterogeneous energy distribution. ${ }^{48}$ Sips $^{49}$ has derived his isotherm by assuming a Langmuir behavior on the homogeneous patches and a Gaussian energy distribution for an exponent of $s<1$. That approach can also be transferred to $s>1$. By superposition of several sigmoidal Sips isotherms, each assigned to a Gaussian energy distribution, nearly any course of an isotherm inside the whole range between type I and VI can be simulated, although the intrinsic interaction with the homogeneous patches is of Langmuir type. ${ }^{50}$ The energy distribution function is then a result of the curve fitting and needs verified by supporting experimental techniques. Hence the analysis of adsorption isotherms is rather complex. To reduce the experimental effort, adsorbents with a strict geometrical pore structure, e.g. zeolites, are preferred for the verification of theoretical adsorption isotherms.

On the theoretical side different principle ways of thinking have to be discerned. Langmuir ${ }^{51}$ pioneered the kinetic approach to the derivation of his adsorption isotherm in 1918. It is later used for the derivation of the $\mathrm{BET},{ }^{36}$ the $\mathrm{GAB},{ }^{39}$ and the FowlerGuggenheim isotherm. ${ }^{52}$ Alternatively the derivation of the isotherms is based on classical thermodynamics or statistical thermodynamics. ${ }^{53}$ The first example of the latter concept has been presented by Fowler and Guggenheim in their deduction of a sigmoidal isotherm. ${ }^{54}$ Also the BET equation can be obtained via statistical thermodynamics. ${ }^{55}$ The derivation of a type $\mathrm{V}$ isotherm similar to that of Sips ${ }^{44}$ and another concerning both monomeric and dimeric adsorbates ${ }^{56}$ are further examples for this approach.

Against this background and based on the original idea of Klotz, ${ }^{19}$ the classical derivation of a sigmoidal isotherm is presented here and applied to the adsorption of water on hydrophobic surfaces. Most examples are referred to activated carbon but the adsorption on a zeolite-analog crystalline material is also presented. All experimental data are taken from the literature.

\section{Methods}

Calculations were performed either by Excel (usual accuracy of 15 decimal points) or SigmaPlot 2000 software for curve fitting by non-linear regression according to the LevenbergMarquardt algorithm. ${ }^{57}$ All experimental data were taken from the literature by graphical conversion of plots to numerical values.

\section{Theory}

The starting point of the presented work is the concept of Klotz ${ }^{19}$ originally and successfully applied to protein interactions with small molecules. ${ }^{20}$ Its application to capillary condensation has to consider that all equilibrium constants involved have to merge into a single one when surface effects with the pore walls can be neglected. Such surface interaction can be induced by primary adsorption sites interacting with the fluid inside the pore, which is either in the gaseous or after condensation in the liquid state. Acid sites can act as nucleation points for the phase transition of water in activated carbon; hydroxy groups at the inner surface of mesoporous silica have the same property. Their concentration surely influences the isotherm. However, when their influence is low, the Klotz equation, already presented in the introduction as eqn (7), reduces to the numeric series:

$$
\theta=\frac{\sum_{i=1}^{m} i q^{i}}{1+\sum_{i=1}^{m} q^{i}}
$$

where $m$ is the maximal association number and $q$ is given by

$$
q=K x
$$

$K$ is discussed later in Section 5. For $m=1$ eqn (14) reduces to that of Langmuir. Furthermore, the application of de L'Hôpital's role yields Henry's law for very low degrees of coverage

$$
\lim _{x \rightarrow 0} \frac{\mathrm{d} \theta}{\mathrm{d} x}=K
$$

and for $x$ going to infinite the result is

$$
\lim _{x \rightarrow \infty} \theta=m \text {. }
$$

With great values of $m$ the calculation using the Klotz equation is very unwieldy. But it can be simplified. The denominator of eqn (14) is a geometric series which can be mathematically transformed to ${ }^{58}$

$$
1+\sum_{i=1}^{m} q^{i}=\frac{1-q^{m+1}}{1-q}
$$

and the series of the numerator is converted by differentiation according to 59

$$
\sum_{i=1}^{m} i q^{i}=\sum_{i=1}^{m} q \frac{\partial}{\partial q} q^{i}=q \frac{\partial}{\partial q}\left(\frac{1-q^{m+1}}{1-q}\right)=\frac{q\left(1-(m+1) q^{m}+m q^{m+1}\right)}{(1-q)^{2}}
$$


so that the Klotz equation reduces to

$$
\theta=\frac{q\left\{1-(1+m) q^{m}+m q^{m+1}\right\}}{(1-q)\left\{1-q^{m+1}\right\}}
$$

In the next step the Klotz equation is extended by allowing the first association constant $K_{1}$ to be different from the following. Defining

$$
K_{1}=C K
$$

yields eqn (7) in the form of

$$
\theta=\frac{C \sum_{i=1}^{m} i q^{i}}{1+C \sum_{i=1}^{m} q^{i}}
$$

Also for that notation the series of expansion can be eliminated. When the denominator is written as

$$
\begin{aligned}
1+C \sum_{i=1}^{m} q^{i} & =C\left\{\frac{1-C}{C}+1+\sum_{i=1}^{m} q^{i}\right\} \\
& =C\left\{\frac{1-C}{C}+\frac{1-q^{m+1}}{1-q}\right\} \\
& =\frac{(1-C)(1-q)+C\left(1-q^{m+1}\right)}{1-q}
\end{aligned}
$$

series (22), being the quotient of eqn (19) and (23), is reduced to

$$
\theta=\frac{C q\left\{1-(1+m) q^{m}+m q^{m+1}\right\}}{(1-q)\left\{1+(C-1) q-C q^{m+1}\right\}}
$$

That equation is nothing else than the $\zeta$-equation which has been derived by Ward et al. ${ }^{37}$ via a longer alternative way applying statistical thermodynamics. It is also identical with the $n$-layer BET isotherm for $q=x .^{36}$ Special cases are obtained for the assumption that the index $i$ is allowed to reach infinite. For $q$ smaller than unity eqn (24) reduces then to

$$
\theta=\frac{C K x}{(1-K x)\{1+(C-1) K x\}} ; \quad K x<1 ; \quad m \rightarrow \infty
$$

For better understanding $q$ is here replaced by $K x$ according to eqn (15). Obviously this is Anderson's ${ }^{39}$ modified BET equation originally developed for the assumption that the heat of adsorption in the second layer and the next following layers is less than the heat of liquefaction.

At last the original BET equation, being Anderson's equation with $K=1$, is shown to be a special case of the Klotz equation. It has to be mentioned that Brunauer et al. ${ }^{36}$ have derived the BET-equation in a similar fashion when the layer-by-layer deposition was formulated by summing-up the covered volume per totally possible volume. One finds eqn (18) and (19) in their derivation with the only difference that they used the infinite instead the numerical series. Also Hill $^{55}$ presented that approach following the concept of statistical thermodynamics with $q=x$, $x<0$ and $m \rightarrow \infty$.

\section{Comparison of the Klotz-isotherm with others}

Fig. 1 and 2 show the sigmoidal course of the Klotz isotherm for the simplest case that all binding constants are the same. At $q=1$ the point of inflection occurs. This point is clearly defined by the original notation of the Klotz isotherm (14) but it is not defined in the simplified form of eqn (20) because it is a singularity. For the practical application it is useful to compare it with other established sigmoidal isotherms. In Fig. 1 the Klotz isotherm has the value of $m=10$ and all other isotherms are fitted to it using $\theta$ values ranging between 0.2 and 0.8 . Within that range the deviation is low, but it is great in the lower and the upper region. In the lower region the Fowler-Guggenheim eqn (4) has a positive deviation while negative deviations occur for the isotherms of Brunauer (11), Sips (12) and DubininAstakhov (13). In the upper region the deviations are reversed. Fig. 2 shows the analog behavior for $m=100$. Only the fit of the BDDT equation ${ }^{42}$ was impossible.

As a result of the isotherm comparison, empirical correlations between the exponents can be calculated. The exponent $s$ of the Sips isotherm, presented in the introduction as eqn (12), can be converted to $m$ by

$$
s=\frac{m}{A\left\{1-\exp \left(-B m^{C}\right)\right\}}
$$

with $A=3.186 \pm 0.007, B=0.525 \pm 0.012$, and $C=0.52 \pm 0.01$. An interconversion is also possible for the Fowler-Guggenheim isotherm presented in the introduction as eqn (4). Its exponent is correlated with $m$ of the present isotherm by

$$
\frac{2 \omega}{R T}=A_{1}\left\{1-\exp \left(-B_{1} m\right)\right\}+A_{2}\left\{1-\exp \left(-B_{2} m\right)\right\}
$$

with $A_{1}=3.40 \pm 0.15, B_{1}=0.22 \pm 0.01, A_{2}=0.88 \pm 0.14$, and $B_{2}=0.031 \pm 0.007$. The corresponding empirical relation between

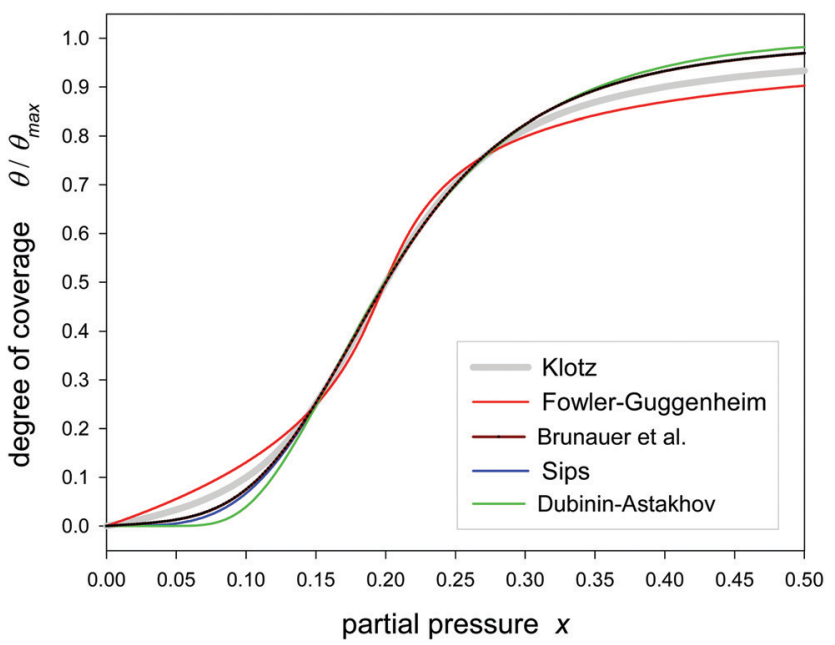

Fig. 1 Fitting of different sigmoidal isotherms in the range of $\theta / \theta_{\max }=$ $0.2-0.8$ to the Klotz isotherm (eqn (24)) calculated with $C=1, K=5$ and $m=10$. 


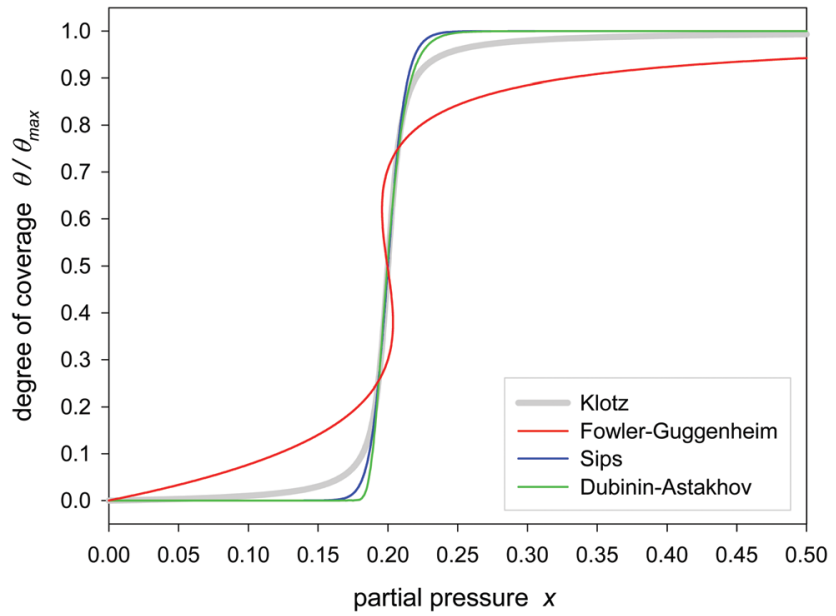

Fig. 2 Fitting of different sigmoidal isotherms in the range of $\theta / \theta_{\max }=$ $0.2-0.8$ to the Klotz isotherm (eqn (24)) calculated with $C=1, K=5$ and $m=100$.

the adsorption constant of Fowler-Guggenheim $\left(K=K_{\mathrm{FG}}\right)$ and the $K$ value of the present isotherm is

$$
K_{\mathrm{FG}}=\frac{K}{A\left\{1-\exp \left(-B m^{C}\right)\right\}}
$$

with $A=8.40 \pm 0.01, B=0.159 \pm 0.007$, and $C=0.74 \pm 0.02$.

These correlations are independent on the respective other isotherm parameters. However, the interconversion of DubininAstakhov to the Klotz isotherm is an interdependent function of both the exponents and the adsorption constants, and therefore not presented here. Further underlying data towards the isotherm interconversion is available in the ESI $\dagger$ (Fig. A1-A3).

While Fig. 1 and 2 comprise only type $\mathrm{V}$ isotherms, Fig. 3 shows that also type IV isotherms are covered when the first adsorption constant is allowed to be greater than the remaining ones $(C>1)$. Considering the case that the first adsorption constant is lower $(C<1)$ the isotherm the first low region is further diminished. The point of inflection is shifted to lower

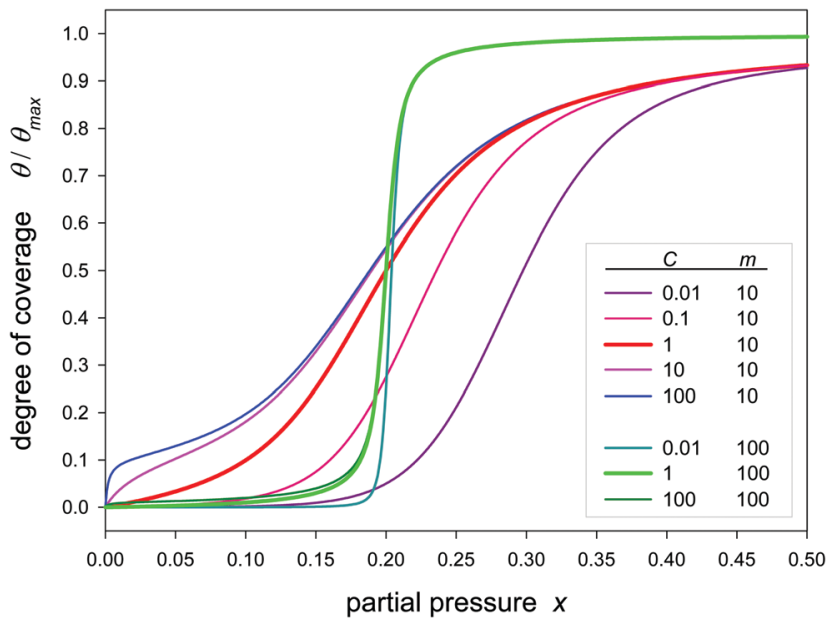

Fig. 3 Plot of the Klotz isotherms (eqn (24)) with different values of $C$ and $m$ for $K=5$. partial pressures $(q<1)$ for $C>1$ and to higher pressures $(q>1)$ for $C<1$. The influence the $K$-values in the second and further adsorption layers is not considered here. That will be the subject of another contribution.

Of special interest are type IV isotherms. In contrast to the present isotherm, all others found in the literature are based on two parallel occurring sorption processes. One describes the adsorption on the adsorbent's functional sites, another comprises a pore filling mechanism. An empirical approach is the combination of a Langmuir and a Sips isotherm favored by Moon and his group. ${ }^{15-18}$ Among the theoretically derived isotherms only the model of Malakhov and Volkhov ${ }^{28}$ after its modification by Rutherford ${ }^{29}$ and the model of Do and $\mathrm{Do}^{34,35}$ are able to map the course of type IV. The latter should be presented here in more detail.

Do and Do have developed their "DD-model" with respect to the adsorption of water on a hydrophobic microporous material, being an activated carbon. In contrast to pure graphene, carbon is characterized by some functional groups which are able to act as primary sorption sites for water. After the surface adsorption a capillary condensation occurs at higher partial pressure which is characterized by a more or less sharp increase of the isotherm. ${ }^{8}$ The starting point of the DD-model is the idea that primarily adsorbed water clusters $A_{\beta} S$ around the functional group $S$ partially detach according to the equilibrium

$$
\mathrm{A}_{\beta} \mathrm{S} \leftrightarrow \mathrm{A}_{\alpha}+\mathrm{A}_{\beta-\alpha} \mathrm{S}
$$

That equilibrium leads then to the following isotherm ${ }^{34,35}$

$$
\theta=f \frac{K_{\mathrm{f}} \sum_{n=1}^{\beta} n x^{n}}{1+K_{\mathrm{f}} \sum_{n=1}^{\beta} x^{n}}+(1-f) \frac{K_{\mu} \sum_{n=\alpha+1}^{\beta} x^{n}}{K_{\mu} \sum_{n=\alpha+1}^{\beta} x^{n}+\sum_{n-\alpha=1}^{\beta} x^{n-\alpha}}
$$

The first term with the fraction $f$ and the thermodynamic adsorption constant $K_{\mathrm{f}}$ is responsible for the clustering at the primary site, the second with the fraction $f$ has been derived from the detachment equilibrium and is characterized by the interaction constant $K_{\mu}$ between the water molecules filling the pores. The latter process starts when the critical clustering $\alpha$ is achieved. The pore filling for both terms is finished at a maximal number of $\beta$. Do and Do assumed in their first article ${ }^{34}$ a value of $\alpha=5$ but did not comment $\beta$. They mentioned that the first term is identical with BET when $\beta$ is infinite. According to the eqn (22)-(24) the first term can be expressed by the $n$-layer BET isotherm. As noticed by Neitsch et $a l^{60}$ the second term can also be simplified by division through

$$
\sum_{n-\alpha=1}^{\beta} x^{n-\alpha}
$$

Then the resulting term is identical with the Sips isotherm. Hence, the detachment of water clusters is equivalent to the Langmuir type desorption of water clusters with the size $\alpha$, and the full isotherm has the simplified general form:

$$
\theta=f \frac{K_{\mathrm{f}} x\left\{1-(1+\beta) x^{\beta}+\beta x^{\beta+1}\right\}}{(1-x)\left\{1+\left(K_{\mathrm{f}}-1\right) x-K_{\mathrm{f}} x^{\beta+1}\right\}}+(1-f) \frac{K_{\mu} x^{\alpha}}{1+K_{\mu} x^{\alpha}} ; \quad \beta \geq \alpha
$$


In their second article the authors of the DD-isotherm assumed that $\alpha$ may be a free fit parameter. ${ }^{35}$ In summary, eqn (30) contains 5 adjustable parameters, namely $f, K_{\mathrm{f}}, K_{\mu}, \alpha$, and $\beta$ (beside the saturation capacity).

The DD-model can be compared with the Klotz isotherm which has only 3 parameters: $K, C$, and $m$. This is shown in Fig. 4 where a synthetic DD-isotherm is calculated with defined parameters and the Klotz-isotherm is fitted to it by non-linear regression. When all values above $x=0.75$ are omitted, a fair match is achieved. Only at higher partial pressure the Klotz isotherm deviates strongly, the greater the exponent $\beta$ of the DD-equation is. Compared with the hybrid DD-model, the Klotz isotherm represents a unified concept where all interactions, which are possible between the water and the surface and in between the water molecules itself, are comprised. This is theoretically preferred although, as discussed later, the DD-model may result in a better fitting of some experimental data. From the mathematical point of view the DD-model (eqn (30)) is a sum of two independent terms, the first describing the surface interaction and the second comprising the cluster formation. But strictly spoken such an additive superposition is only applicable when the terms are responsible for adsorption on distinct sites, for example inside the pores or on the external surface, or generally on a heterogeneous adsorbent. Admittedly, the Klotz model is also based on sums, but it is a quotient of two series of expansions. Hence the primary sorption and the cluster formation are inter-dependent processes.

\section{Application to experimental data of water sorption on carbon}

Numerous reports are available in the literature on delivering experimental data of type $\mathrm{V}$ and IV adsorption and desorption isotherms. As an example, the sorption of water on different carbons is considered here. To concentrate solely on the isotherms, the background concerning the chemical and morphological nature of the carbon is omitted here. In the beginning of the application review, reference is made to the work of Rutherford $^{63}$ presenting the water adsorption isotherm on a carbon molecular sieve over a large range of partial pressure. Rutherford has accomplished a fitting of his data with his modified 4 parameter hybrid model (eqn (2) and (3)). Fig. 5 shows that the application of the 3-parameter Klotz isotherm also yields fair results.

Activated carbons differ in their fraction of functional groups. Thus, heat treatment under argon gives very hydrophobic carbons with a sharp increasing isotherm at high partial pressure while oxidation results in considerable adsorption already at low pressure followed by only a smooth pore filling increase. ${ }^{9}$ Fig. 6 shows that the Klotz isotherm covers a range of different carbons.

However, some examples have to be reported for which the model deviates. The example of Fig. 7 shows that the experiment is not covered at medium pressures before the pore filling sets in. This is because the model is limited to only one

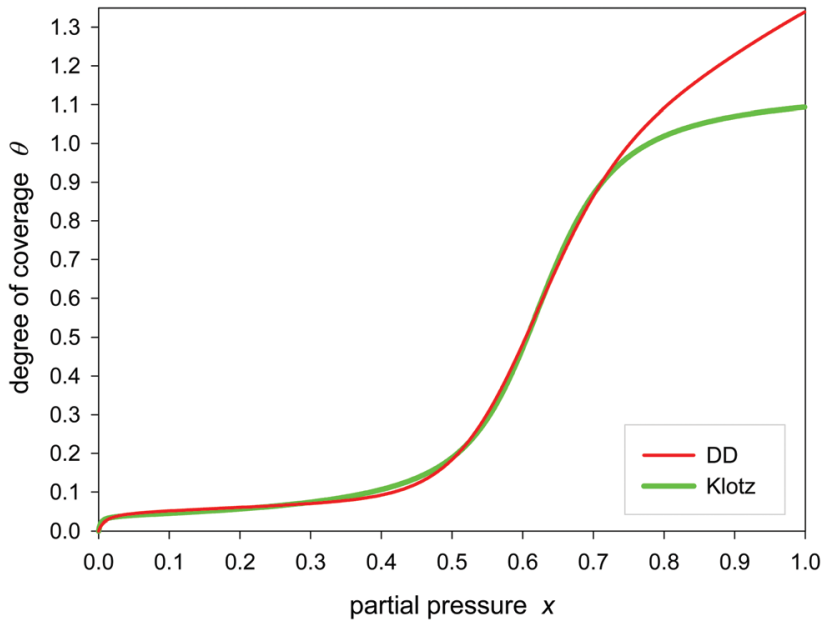

Fig. 4 Fitting of the Klotz isotherm (eqn (24)) to the DD-model (eqn (30)) calculated with $f=0.05, K_{\mathrm{f}}=100, \alpha=10, K_{\mu}=100, \beta=20$. Within the range of $x=0-0.75$. Regression analysis: $K=1.59, C=200$, and $m=30$.

separate surface layer interaction. A respective extension of the model is obviously necessary. The DD-model can easily be fitted to that experiment, but as outlined before, it fails from the theoretical point of view.

Another example is focused on the high pressure region. As shown in Fig. 8, the isotherm is fully covered by a hybrid model such as DD but not by the Klotz model. To change the behavior of the Klotz model at high pressures it may be extended, for example by adding a possible linear correction according to

$$
\theta=\frac{C q\left\{1-(1+m) q^{m}+m q^{m+1}\right\}}{(1-q)\left\{1+(C-1) q-C q^{m+1}\right\}}+K_{\mathrm{L}} x
$$

The linear term represents an additional parallel occurring sorption on separate sites.

Table 1 shows a compilation of different experiments taken from the literature. The underlying plots are those already discussed; further are shown in the supplementary information. Table 1 also contains a statistical evaluation. The average relative error (ARE) provides a measure for comparison. In order to compare the theoretical eqn (24) with the empirical linear extension (eqn (31)) both fittings were characterized by the Akaike criterion for model selection. It is defined in its corrected form ${ }^{76}$ by the residual number of squares $\sigma^{2}$, the number of used experimental points $N$, and the number of parameters $k$ according to

$$
\mathrm{AICc}=-2 \ln \sigma^{2}+2 k+\frac{2 k(k+1)}{(N-k-1)}
$$

That model, which gives the lowest value of AICc, is the best from the statistical view. ${ }^{77}$ However, the AICc values in Table 1 are not differing very much. Hence both models can by applied. A problem is that the linear extension is assumed also to be valid in the first part of the full isotherm where it is influencing the $C$-value. When the capillary condensation is regarded as a phenomenon of the porous nature of the adsorbent and the linear increase is due to the adsorption on its non-porous 


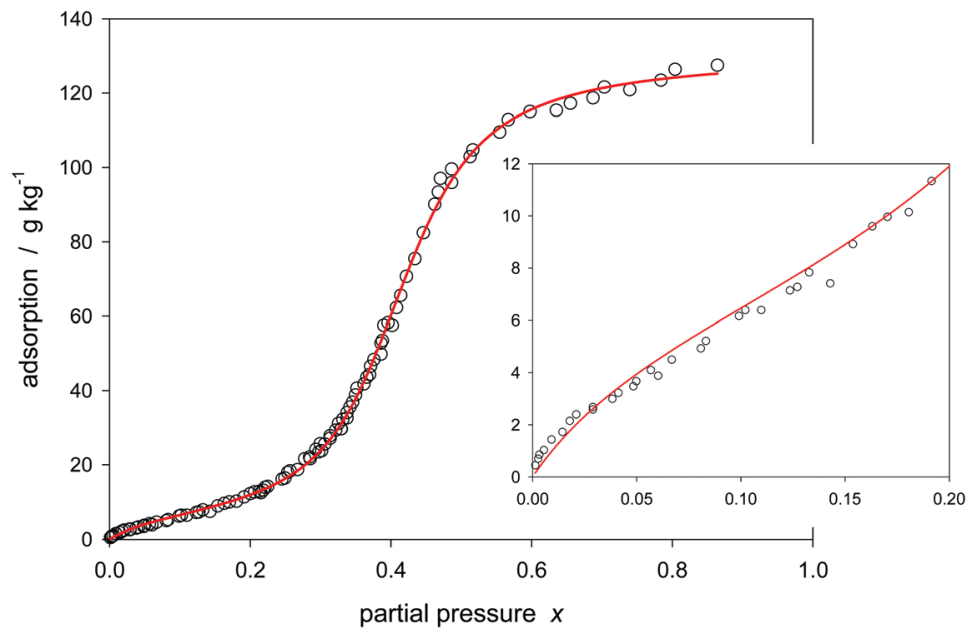

Fig. 5 Klotz isotherm (eqn (24)) for modeling of water adsorption on carbon molecular sieve no. 19 (Table 1).

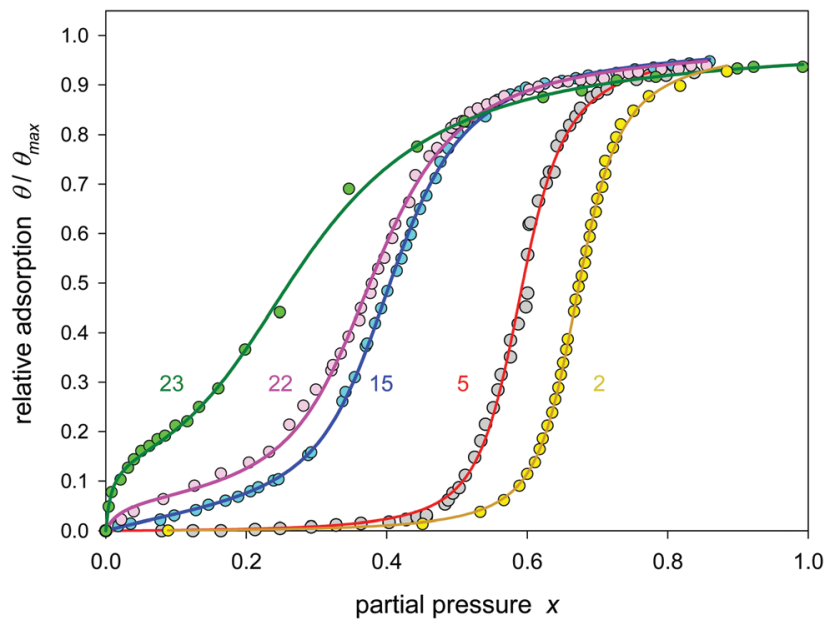

Fig. 6 Klotz isotherm (eqn (24)) for modeling of water adsorption on activated carbon no. 2, 5, 15, 22, and 23 (Table 1).

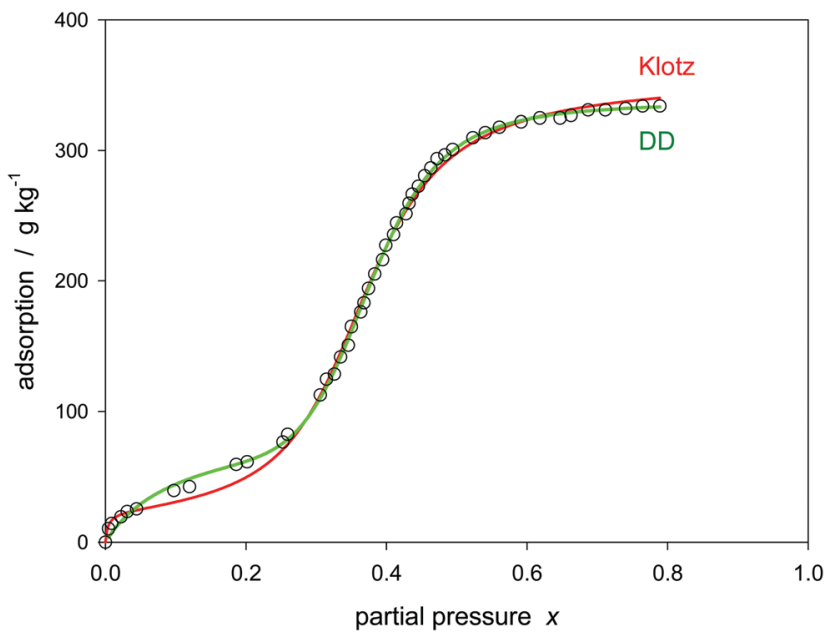

Fig. 7 Model of Klotz (eqn (24)) and DD (eqn (30)) for water adsorption on carbon no. 26 (Table 1).

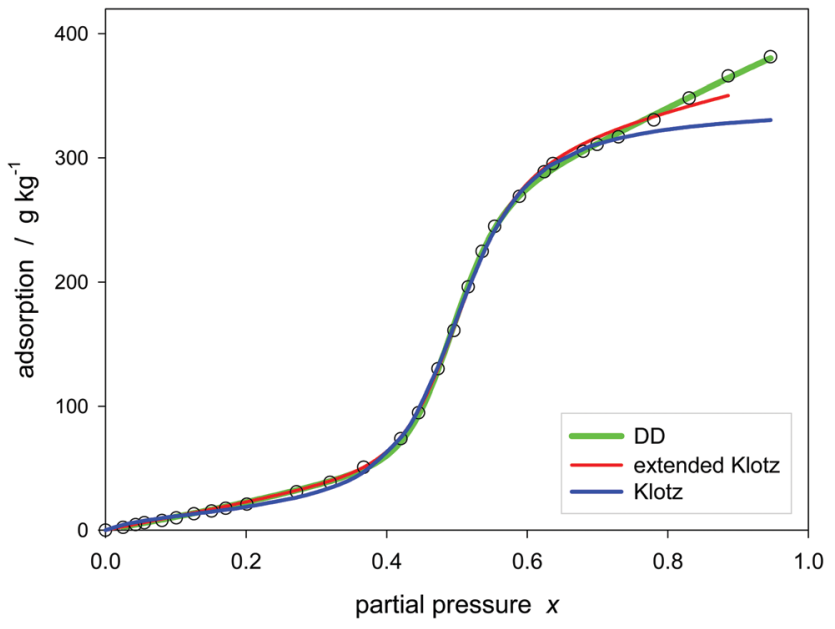

Fig. 8 Model of Klotz (eqn (24)), extended Klotz (eqn (31)), and DD (eqn (30)) for water adsorption on carbon no. 14 (Table 1).

counterpart, a chance for separating both phenomena exists. A respective method is introduced in the $\mathrm{N}_{2}$-adsorption porosimetry by the so-called $\alpha_{s}$-plot. $^{78}$

The analysis of the experiments listed in Table 1 is ordered due to increasing $C$-parameters. It contains as well examples for type V with $C \leq 0$, as type IV examples with $C>0$. The $K$-values are ranging between 1.5 and 2.5. They should reflect the binding between the water molecules independent on the surface interaction. In other words, $K$ defines the capillary condensation. As shown in Fig. 3, for great values of $m$ the value of $1 / K$ is identical with the partial pressure of the inflection point of the isotherm. In the case of $K=1$ the capillary effect is absent. Thermodynamically $K$ defines the equilibrium of

$$
\mathrm{H}_{2} \mathrm{O}+\left(\mathrm{H}_{2} \mathrm{O}\right)_{n-1} \leftrightarrow\left(\mathrm{H}_{2} \mathrm{O}\right)_{n}
$$

which is given by

$$
K=\frac{\left[\left(\mathrm{H}_{2} \mathrm{O}\right)_{n}\right]}{\left[\mathrm{H}_{2} \mathrm{O}\right]\left[\left(\mathrm{H}_{2} \mathrm{O}\right)_{n-1}\right]}
$$


Table 1 Parameters of the Klotz-isotherm (eqn (24) and (31)) found by non-linear regression of experimental data. Plots of the underlying non-linear regressions are shown in Fig. 5-12, additional ones: see ESI. Statistics: R: regression coefficient. N: number of used experimental values. ARE: standard error related to maximal loading. AlCc: Corrected Akaike criterion ${ }^{76}$

\begin{tabular}{|c|c|c|c|c|c|c|c|c|c|c|c|c|c|}
\hline \multirow[b]{2}{*}{ No. } & \multirow[b]{2}{*}{ Literature } & \multirow[b]{2}{*}{ Figures } & \multirow[b]{2}{*}{ Adsorbent } & & \multicolumn{5}{|l|}{ Parameters } & \multicolumn{4}{|c|}{ Statistics } \\
\hline & & & & & $Q_{\max } / \mathrm{g} \mathrm{kg}^{-1}$ & C & $K$ & $m$ & $K_{\mathrm{L}}$ & $R$ & $N$ & $\mathrm{ARE} / \%$ & AICc \\
\hline & & & Carbon & & & & & & & & & & \\
\hline \multirow[t]{2}{*}{1} & 62 & 3 & CFK12 & ads & $253 \pm 2.1$ & $0.178 \pm 0.13$ & $2.336 \pm 0.1290$ & $9.0 \pm 1.6$ & 0.000 & 0.99918 & 35 & 1.32 & 214 \\
\hline & & 3 & CFK12 & ads & $202 \pm 52$ & $0.034 \pm 0.24$ & $2.861 \pm 3.4700$ & $8.8 \pm 6.6$ & $0.224 \pm 0.241$ & 0.99947 & 35 & 1.36 & 201 \\
\hline 2 & 63 & $5 a$ & CS II & ads & $314 \pm 2.5$ & $0.19 \pm 0.05$ & $1.494 \pm 0.0036$ & $51.3 \pm 2.7$ & 0.000 & 0.99955 & 37 & 0.89 & \\
\hline \multirow[t]{2}{*}{3} & 64 & 3 & AC-1 & ads & $1152 \pm 14$ & $0.20 \pm 0.10$ & $1.278 \pm 0.0018$ & $106 \pm 8$ & 0.000 & 0.99890 & 26 & 1.58 & \\
\hline & & 3 & AC-1 & des & $1089 \pm 14$ & $0.20 \pm 0.30$ & $1.596 \pm 0.0023$ & $197 \pm 22$ & 0.000 & 0.99670 & 30 & 3.00 & \\
\hline 4 & 63 & $5 \mathrm{a}$ & KUA1 & ads & $279 \pm 1$ & $0.20 \pm 0.05$ & $1.941 \pm 0.0179$ & $23.9 \pm 1.6$ & 0.000 & 0.99969 & 34 & 0.82 & \\
\hline 5 & 9 & 31 & A & ads & $361 \pm 5.6$ & $0.21 \pm 0.11$ & $1.700 \pm 0.0109$ & $42.1 \pm 4.8$ & 0.000 & 0.99796 & 49 & 2.32 & \\
\hline 6 & 65 & $2 \mathrm{a}$ & MSC-30 & ads & $1379 \pm 9.0$ & $0.22 \pm 0.05$ & $1.351 \pm 0.0021$ & $62.1 \pm 2.9$ & 0.000 & 0.99985 & 25 & 0.62 & \\
\hline \multirow[t]{2}{*}{7} & 66 & 2 & $\mathrm{H}$ & ads & $184 \pm 0.9$ & $0.32 \pm 0.05$ & $1.561 \pm 0.0049$ & $28.4 \pm 1.2$ & 0.000 & 0.99994 & 18 & 0.46 & \\
\hline & & 2 & $\mathrm{H}$ & des & $178 \pm 1.4$ & $>100$ & $2.069 \pm 0.0061$ & $67.6 \pm 4.8$ & 0.000 & 0.99954 & 18 & & \\
\hline \multirow[t]{3}{*}{8} & 67 & 6 & $\mathrm{~N}-19$ & ads & $565 \pm 7.3$ & $0.98 \pm 0.45$ & $1.453 \pm 0.0032$ & $47.5 \pm 2.5$ & 0.000 & 0.99940 & 22 & 1.16 & \\
\hline & & 6 & $\mathrm{~N}-19$ & des & $510 \pm 12$ & $1.0 \pm 6$ & $1.836 \pm 0.0021$ & $276 \pm 37$ & 0.000 & 0.99211 & 28 & 4.80 & 278 \\
\hline & & & & des & $472 \pm 45$ & $1.9 \pm 71$ & $1.833 \pm 0.0014$ & $341 \pm 39$ & $0.119 \pm 0.145$ & 0.99500 & 28 & 4.33 & 272 \\
\hline 9 & 68 & $5 \mathrm{a}$ & MSC3K & ads & $134 \pm 0.5$ & $1.2 \pm 0.2$ & $2.002 \pm 0.0020$ & $39.5 \pm 0.9$ & 0.000 & 0.99976 & 48 & 0.76 & \\
\hline \multirow[t]{2}{*}{10} & 66 & 2 & $\mathrm{R} 1$ & ads & $165 \pm 2.7$ & $1.22 \pm 0.36$ & $1.761 \pm 0.0153$ & $13.3 \pm 1.1$ & 0.000 & 0.99953 & 19 & 1.14 & \\
\hline & & 2 & R1 & des & $164 \pm 1.7$ & $2.67 \pm 1.88$ & $2.188 \pm 0.0146$ & $25.4 \pm 2.1$ & 0.000 & 0.99918 & 19 & 1.79 & \\
\hline \multirow[t]{2}{*}{11} & 69 & S1 (ESI) & A7 & ads & $268 \pm 1.3$ & $1.24 \pm 0.18$ & $2.370 \pm 0.0062$ & $18.5 \pm 0.5$ & 0.000 & 0.99979 & 34 & 0.69 & 167 \\
\hline & & S1 (ESI) & A7 & ads & $243 \pm 7.8$ & $0.45 \pm 0.18$ & $2.414 \pm 0.0276$ & $17.8 \pm 1.0$ & $0.137 \pm 0.047$ & 0.99980 & 34 & 0.75 & 168 \\
\hline 12 & 62 & 3 & CFC20 & ads & $234 \pm 1.2$ & $1.68 \pm 0.54$ & $2.279 \pm 0.0051$ & $27.4 \pm 0.9$ & 0.000 & 0.99932 & 30 & 0.96 & \\
\hline 13 & 70 & 1 & AZ-46-0 & ads & $318 \pm 3$ & $300 \pm 450$ & $1.977 \pm 0.0147$ & $23.6 \pm 1.2$ & 0.000 & 0.99933 & 27 & 1.54 & \\
\hline \multirow[t]{2}{*}{14} & 71 & $3 \mathrm{a}$ & & ads & $346 \pm 2.1$ & $8.27 \pm 2.26$ & $1.978 \pm 0.0050$ & $25.7 \pm 0.6$ & 0.000 & 0.99981 & 26 & 0.73 & 139 \\
\hline & & $3 a$ & & ads & $269 \pm 7.7$ & $0.085 \pm 0.12$ & $2.081 \pm 0.1701$ & $21.3 \pm 6.1$ & $0.390 \pm 0.053$ & 0.99980 & 26 & 1.66 & 149 \\
\hline 15 & 9 & 41 & B & ads & $370 \pm 1.3$ & $2.9 \pm 0.5$ & $2.440 \pm 0.0051$ & $19.0 \pm 0.4$ & 0.000 & 0.99973 & 52 & 0.84 & \\
\hline \multirow[t]{3}{*}{16} & 72 & 1 (ESI) & PIT11 & ads & $1040 \pm 13$ & $3.1 \pm 2.2$ & $1.273 \pm 0.0031$ & $48.0 \pm 2.1$ & 0.000 & 0.99933 & 27 & 1.23 & \\
\hline & & 1 (ESI) & PIT11 & des & $927 \pm 17$ & $>50$ & $1.641 \pm 0.0054$ & $67.4 \pm 5.2$ & 0.000 & 0.99838 & 15 & 2.25 & 139 \\
\hline & & 1 (ESI) & PIT11 & des & $836 \pm 44$ & $4.7 \pm 10$ & $1.635 \pm 0.0030$ & $83.4 \pm 6.7$ & $0.117 \pm 0.013$ & 0.99936 & 15 & 1.72 & 132 \\
\hline 17 & 9 & 31 & $\mathrm{E}$ & ads & $371 \pm 3$ & $3.4 \pm 0.8$ & $2.477 \pm 0.0084$ & $17.1 \pm 0.5$ & 0.000 & 0.99940 & 60 & 1.20 & \\
\hline \multirow[t]{2}{*}{18} & 68 & $5 b$ & HF CM & ads & $109 \pm 0.5$ & $6.1 \pm 1.0$ & $2.609 \pm 0.0110$ & $12.4 \pm 0.2$ & 0.000 & 0.99979 & 31 & 0.71 & 96 \\
\hline & & $5 \mathrm{~b}$ & HF CM & ads & $104 \pm 5$ & $6.3 \pm 1.2$ & $2.626 \pm 0.0210$ & $12.9 \pm 0.6$ & $0.058 \pm 0.050$ & 0.99961 & 31 & 0.75 & 98 \\
\hline 19 & 61 & 1 & $5 \mathrm{~A}$ & ads & $132 \pm 0.6$ & $6.9 \pm 1.1$ & $2.393 \pm 0.0061$ & $18.4 \pm 0.3$ & 0.000 & 0.99945 & 98 & 0.99 & \\
\hline 20 & 73 & 1 & DS-A & ads & $540 \pm 5.3$ & $9.2 \pm 3.6$ & $1.747 \pm 0.0097$ & $17.1 \pm 0.5$ & 0.000 & 0.99947 & 23 & 1.01 & \\
\hline 21 & 63 & $5 \mathrm{a}$ & CFS97 & ads & $180 \pm 0.7$ & $10.5 \pm 3.8$ & $1.682 \pm 0.0024$ & $26.2 \pm 0.3$ & 0.000 & 0.99918 & 35 & 0.61 & \\
\hline 22 & 9 & 41 & $\mathrm{C}$ & ads & $367 \pm 1.8$ & $18.2 \pm 9.7$ & $2.600 \pm 0.0104$ & $15.8 \pm 0.4$ & 0.000 & 0.99918 & 51 & 1.32 & \\
\hline 23 & 70 & 1 & AZ-46-24 & ads & $363 \pm 2$ & $37.2 \pm 7.0$ & $3.385 \pm 0.0540$ & $7.0 \pm 0.2$ & 0.000 & 0.99962 & 26 & 1.03 & \\
\hline \multirow[t]{2}{*}{24} & 74 & 3 & CAC & ads & $393 \pm 3.2$ & $46 \pm 65$ & $1.862 \pm 0.0106$ & $21.5 \pm 0.8$ & 0.000 & 0.99948 & 21 & 1.31 & 139 \\
\hline & & 3 & CAC & ads & $315 \pm 14.0$ & $40 \pm 60$ & $1.864 \pm 0.0071$ & $29.2 \pm 2.3$ & $0.237 \pm 0.056$ & 0.99975 & 21 & 1.15 & 127 \\
\hline \multirow[t]{2}{*}{25} & 74 & 3 & LAC1 & ads & $231 \pm 5.4$ & $4 \pm 2$ & $2.843 \pm 0.0951$ & $6.4 \pm 0.8$ & 0.000 & 0.99786 & 21 & 2.21 & 138 \\
\hline & & 3 & LAC1 & ads & $153 \pm 10.0$ & $92 \pm 400$ & $3.416 \pm 0.1054$ & $10.0 \pm 0.9$ & $0.487 \pm 0.103$ & 0.99924 & 21 & 2.04 & 120 \\
\hline 26 & 9 & 31 & $\mathrm{D}$ & ads & $360 \pm 12$ & $93 \pm 60$ & $2.698 \pm 0.0310$ & $15.7 \pm 0.4$ & 0.000 & 0.99891 & 47 & 1.53 & \\
\hline & & & $(\mathrm{Fe}) \mathrm{AlPO}_{4}-5$ & & & & & & & & & & \\
\hline 27 & 4 & 8 & FAPO & $\mathrm{Fe}$ & $189 \pm 3.6$ & $>50$ & $5.363 \pm 0.0090$ & $113 \pm 8$ & 0.000 & 0.99688 & 24 & 2.68 & \\
\hline 28 & 75 & $\mathrm{~B} 1,25^{\circ} \mathrm{C}$ & AQSOA-Z01 & $\mathrm{Fe}$ & $188 \pm 1.5$ & $15 \pm 50$ & $5.417 \pm 0.0141$ & $55 \pm 3$ & 0.000 & 0.99951 & 19 & 1.44 & 100 \\
\hline & & B1, $25{ }^{\circ} \mathrm{C}$ & AQSOA-Z01 & $\mathrm{Fe}$ & $169 \pm 2.4$ & $0.38 \pm 0.22$ & $5.425 \pm 0.0190$ & $62 \pm 6$ & $0.380 \pm 0.023$ & 0.99956 & 19 & 1.66 & 107 \\
\hline & & $\mathrm{B} 2,45{ }^{\circ} \mathrm{C}$ & AQSOA-Z01 & $\mathrm{Fe}$ & $182 \pm 1.1$ & $>50$ & $4.075 \pm 0.0053$ & $57 \pm 1$ & 0.000 & 0.99978 & 22 & & \\
\hline & & $\mathrm{B} 2,45{ }^{\circ} \mathrm{C}$ & AQSOA-Z01 & $\mathrm{Fe}$ & $162 \pm 1.2$ & $0.07 \pm 0.02$ & $4.145 \pm 0.0220$ & $48 \pm 3$ & $0.372 \pm 0.012$ & 0.99993 & 22 & 0.65 & 78 \\
\hline 29 & 3 & $3 \mathrm{a}, 60{ }^{\circ} \mathrm{C}$ & AQSOA-Z01 & $\mathrm{Fe}$ & $203 \pm 3$ & $0.06 \pm 0.16$ & $4.102 \pm 1.0900$ & $16 \pm 9$ & 0.000 & 0.99859 & 15 & 2.50 & 90 \\
\hline & & $3 \mathrm{a}, 60{ }^{\circ} \mathrm{C}$ & AQSOA-Z01 & $\mathrm{Fe}$ & $182 \pm 15$ & $0.02 \pm 0.09$ & $4.484 \pm 2.6000$ & $16 \pm 11$ & $0.153 \pm 0.098$ & 0.99956 & 15 & 2.35 & 95 \\
\hline 30 & 3 & $3 \mathrm{c}, 45{ }^{\circ} \mathrm{C}$ & AQSOA-Z05 & & $219 \pm 4$ & $0.03 \pm 1.09$ & $2.983 \pm 0.7200$ & $20 \pm 12$ & 0.000 & 0.99866 & 13 & 2.50 & \\
\hline
\end{tabular}

$\left[\mathrm{H}_{2} \mathrm{O}\right]$ represents the outer partial pressure while $n$ is identical with the index number $i$ of the series of expansion (eqn (14)) and can have values between

$$
2<n<m
$$

Hence $K$ is the cluster formation constant and $R T \ln K$ defines the relative evaporation energy. Interestingly the $K$ values decrease with increasing values of the maximal loading $Q_{\max }$ (Fig. A21 ESI $\dagger$ ) suggesting that a small pore size diminishes the average binding strength in the pore filling liquid.
But a sound interpretation in that direction would require samples with monodispersed pore diameters.

With respect to the basic series of expansion (eqn (14)) the exponent $m$ is a measure of the maximal cluster size. It depends strongly on the employed isotherm. Conversions of that exponent to that of other theoretical sigmoidal isotherms have already been mentioned. Here, the examples listed in Table 1, range from 7 to values above 300 . The value of $m$ can be compared with cluster sizes in non-restricted neat bulk water: Average cluster sizes of some hundred are discussed in the literature. ${ }^{79}$ On the other hand, the hydrogen bond network of 
water is altered inside the pores of carbon materials by the confining geometry alone. For carbon nano-tubes strong effects on the water structure are reported, based on experiment ${ }^{80}$ and simulation. ${ }^{81}$ Due to the confinement, the clusters are assumed to be smaller. But after all, the question remains how a cluster is defined. For example, a recent study of molecular modeling considers cluster sizes of water during its adsorption in activated carbon ranging from 10 to $5000^{65}$ while recent smallangle neutron scattering experiments support the conclusion that the cluster size remains constant throughout the sorption process. $^{82}$

At last, two examples concerning the adsorption-desorption hysteresis are discussed. The $\mathrm{H} 2$ type hysteresis shown in Fig. 9 is characterized by $C=1.2, K=1.76, m=13$ and a saturation value of $Q_{\max }=165 \mathrm{~g} \mathrm{~kg}^{-1}$. The desorption starts at the same ideal saturation point, but the decrease with decreasing $x$ is at first smaller compared to adsorption, only later the desorption proceeds with a stronger fall compared to the ramp of adsorption. The desorption is characterized by $C=2.7, K=2.19, m=25$ and $Q_{\max }=164 \mathrm{~g} \mathrm{~kg}^{-1}$. According to the classical view, the hysteresis is generally caused by the geometries of the vaporliquid interface of the partially filled pores. Two different geometries are possible for the same vapor pressure only depending on the history of their formation. ${ }^{83}$ The change of geometry, which can be generally interpreted as a relaxation process, ${ }^{35}$ is irreversible but after all a thermodynamical equilibrium is achieved both in the adsorption and desorption branch. Whereas the classical interpretation is due to a different vapor-liquid interface, the analysis of the isotherms by the Klotz equation is solely based on the different average sizes of the water clusters. It is important to note that different cluster sizes are correlated with different $K$-values: The larger clusters have a greater internal binding strength, the density of water is therefore considered to be somewhat greater, and the vapor pressure is smaller. Different binding constants have already been presented by Do and Do during the interpretation of the hysteresis of water in carbon considering the parameters of

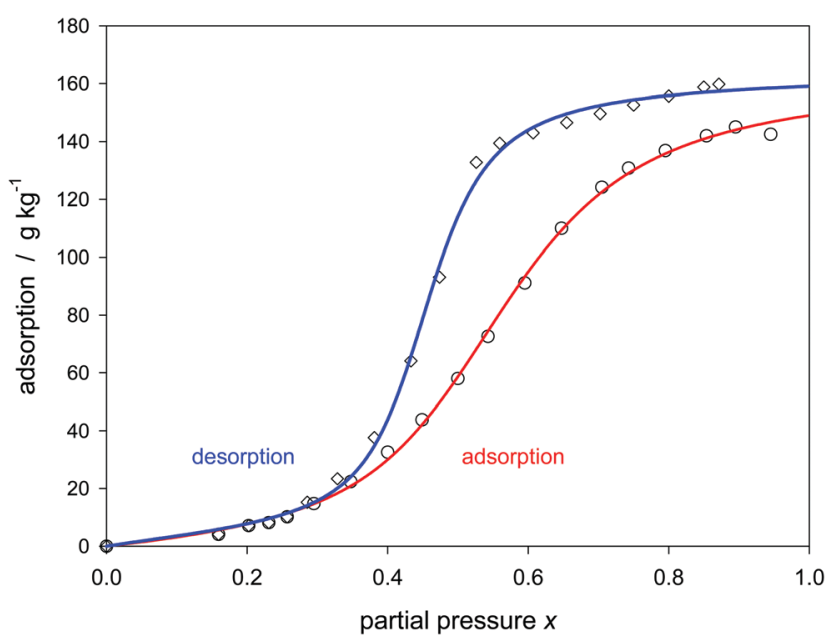

Fig. 9 Hysteresis of water sorption on activated carbon no. 10 (Table 1) described by the Klotz isotherm (eqn (24)).

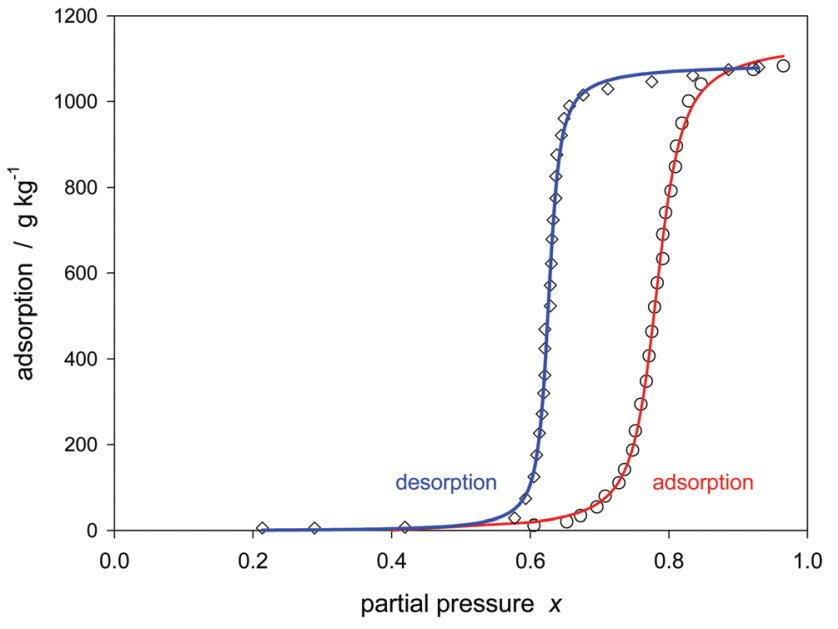

Fig. 10 Hysteresis of water sorption on activated carbon no. 3 (Table 1) described by the Klotz isotherm (eqn (24)).

their own isotherm. The parameter $K_{\mu}$ of the Sips term (see eqn (30)) was greater for the desorption compared to adsorption. ${ }^{35}$ Here, also the $C$-values are different. However, their accuracy is rather low for the desorption branch so that that a discussion is not indicated.

Fig. 10 shows the adsorption-desorption hysteresis of another activated carbon material. The isotherms are much more steep. The adsorption branch is characterized by $C=0.2$, $K=1.278$, and $m=106$, the desorption branch by $C=0.2$, $K=1.596$, and $m=197$. Again the inner binding strength $K$ of the liquid is greater for the desorption, significantly exceeding the error limits of \pm 0.002 . However the course of the isotherms near the partial pressure of unity is not as expected. The extrapolation of the isotherms to infinite $x$ does not result in the same saturation value for both branches. Around $x=0.9$ both branches cross. Such a phenomenon is also observed in case of carbon no. 17 shown in Fig. A15 of the ESI. $\dagger$ Provided the experimental basis is correct, the isotherm seems to fail in the high pressure region. The reason is unclear. Perhaps the change of the average cluster size has an extra influence on the theoretical background of the isotherm.

\section{Application to experimental data concerning aluminophosphate molecular sieves}

As already mentioned in the introduction, the isotherms are principally influenced by the energy distribution of the sorption sites. Usually the activated carbons have a pore size distribution, and the surface contains statistically distributed functional sites. $^{8}$ Therefore these materials can be regarded as heterogeneous. ${ }^{84}$ Also so-called carbon molecular sieves with a pore size below $1 \mathrm{~nm}$, like that presented in Fig. 5, have a pore size distribution. ${ }^{29}$ In contrast, the Klotz equation is based on a homogeneous energy distribution and it has been only assumed that the heterogeneity has negligible minor effects. Therefore adsorbents, 
which are characterized both by a uniform pore size and a uniform internal pore surface, are of interest for the validation of the present isotherm. Sigmoidal isotherms concerning the adsorption of water are also found for aluminophosphates. $\mathrm{AlPO}_{4}$ which is isoelectronic with $\mathrm{SiO}_{4}$ can be crystallized to zeolite-analog microporous materials. When the $\mathrm{P} / \mathrm{Al}$ ratio is unity, these materials are neutral and hydrophobic; they can adsorb water by cluster formation. ${ }^{85}$ The isotherms are usually strongly sigmoidal. ${ }^{3-6}$ $\mathrm{AlPO}_{4}-5$ has the AFI type zeolite structure and contains 1-dimensional micropores with a diameter of $0.742 \mathrm{~nm} .^{86}$

The materials, presented in the following, contain some iron in addition. ${ }^{3-5}$ Fig. 11 shows that the experimental water sorption isotherm follows eqn (24). Another literature source ${ }^{5,50,75}$ has the advantage that it contains a XRD spectrum that proves the crystallographic structure. Also a $\mathrm{N}_{2}$ adsorption at $77 \mathrm{~K}$ is provided in that literature. It shows that after micropore filling a further linear increase follows due to mesopore sorption. Both types of pores have an impact on the water sorption isotherm. As shown in Fig. 12, the first exhibit the sigmoidal increase, the second can be approximated by a linear function paralleling the course of the $\mathrm{N}_{2}$ sorption. The underlying experimental data has been already presented as an example for a "universal isotherm" which is built-up by summation of two sigmoidal Sips-isotherms. Both represent a specific energy distribution of a totally heterogeneous adsorbent. ${ }^{50}$ Since at least the mesopores are indeed heterogeneous, the combination of the present isotherm (eqn (24)) with the Sips part of that literature ${ }^{50}$ is an alternative for the linear function used here. (see Fig. A22 ESI $\dagger$ ). The advantage of the linear function is that is has only one parameter. But an influence on the $C$-value remains, and as a result, the theoretical interpretation of $C$ is questioned. The application of the present isotherm to other examples of water sorption on aluminophosphate molecular sieves is shown in the ESI $\dagger$ (Fig. A23 and A24).

One might guess that eqn (24) can be applied for all water sorption isotherms on aluminophosphate molecular sieves. However, that is not the case. A further example, ${ }^{6}$ shown in

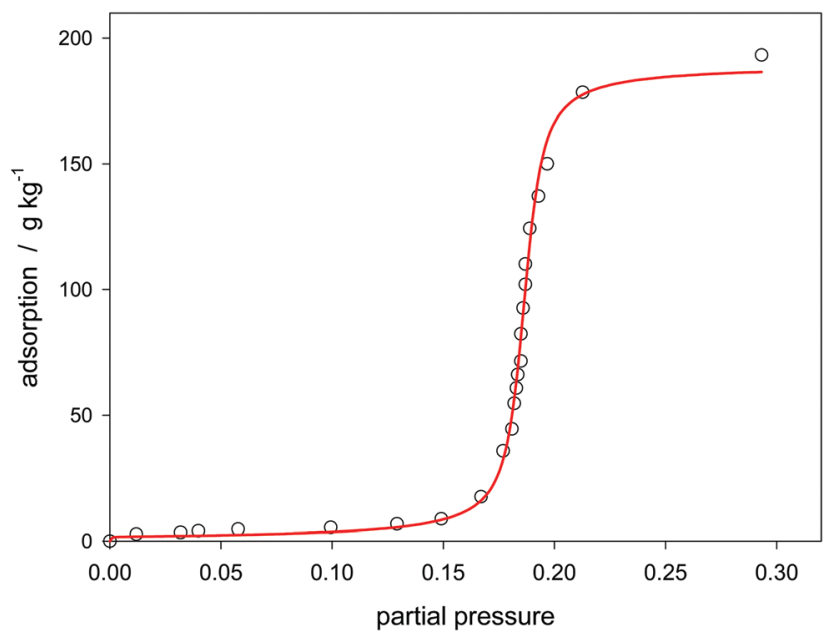

Fig. 11 Adsorption of water on ferro aluminophosphate molecular sieve no. 27 (Table 1) at $25^{\circ} \mathrm{C}$ modeled by the Klotz isotherm (eqn (24)).

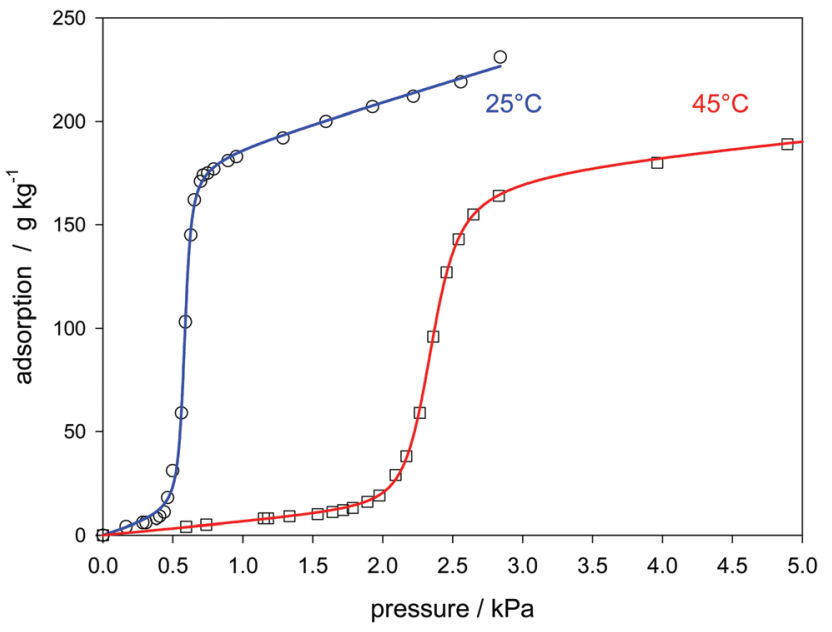

Fig. 12 Model of the extended Klotz eqn (31) applied to the adsorption of water on an ferro aluminophosphate molecular sieve no 28 (Table 1).

Fig. A25 of the ESI, $\dagger$ reveals that obviously the first part of the type IV isotherm cannot be fitted. One has to assume that not only a monolayer but a multilayer is formed at that stage. This possibility is not covered by the present model. The solution of that problem will be addressed in a future publication of the author.

\section{Conclusion}

Based on straightforward considerations presented by Klotz in $1946,{ }^{19}$ an isotherm is derived describing the sorption of type IV and type IV. The equation resembles the $n$-layer BET equation, but instead of the partial pressure it is based on the product of the partial pressure with a constant $K . K$ is interpreted as the thermodynamic constant of the adsorbate clustering inside the adsorbent pores. Alternatively $R T \ln K$ defines the relative evaporation energy compared to the bulk status. The exponent $m$, which corresponds to the number of layers in the BET theory, is here considered to represent the maximal cluster size.

The isotherm is compared with the model of Do and Do. ${ }^{35}$ Whereas the latter model is a hybrid one, essentially consisting of a superposition of the $n$-layer BET and the Sips equation, the present model has only a single term, describing an interdependent primary sorption and cluster formation. An analogous consideration refers to a recently published "universal isotherm". 50

The new isotherm is expected to describe the adsorption of strongly polar adsorbates in the pores of a hydrophobic solid where an adsorbate clustering or capillary condensation can occur. The adsorption of water on microporous hydrophobic carbons is an example for that type of interaction, and numerous experiments are found in the literature.

Therefore the new isotherm was applied to such experimental results. The isotherm successfully maps numerous data of the literature, including adsorption-desorption hysteresis. However, the interpretation of the obtained parameters has to be careful. A strong accuracy of the underlying data is mandatory, 
and the parameters have to be correlated to the results of other characterization methods. The latter is omitted in the present study for carbon-based materials.

In contrast, crystalline aluminophosphate molecular sieves have precisely defined mono-sized micropores beside a heterogeneous mesopore fraction, and the water sorption isotherm has a sigmoidal course. Also in that case the model has been successfully applied.

Nevertheless, experimental data which cannot be covered by the isotherm have been identified. While the present model has only a single parameter for the interaction with the inner porous surface, future work has to consider that interaction in more detail.

\section{Conflicts of interest}

There are no conflicts to declare.

\section{References}

1 K. W. S. Sing, Reporting physisorption data for gas/solid systems, Pure Appl. Chem., 1982, 54, 2201-2218.

2 T. Kohler, M. Hinze, K. Müller and W. Schwieger, Temperature independent description of water adsorption on zeotypes showing a type V adsorption isotherm, Energy, 2017, 135, 227-236.

3 H. W. B. Teo, A. Chakraborty and W. Fun, Improved adsorption characteristics data for AQSOA types zeolites and water systems under static and dynamic conditions, Microporous Mesoporous Mater., 2017, 242, 109-117.

4 S. Cho, D. A. Cha, Y. H. Hwang, O. K. Kwon and T. Hwang, Adsorbent layer for adsorption hat pump prepared with the surface-modified ferroaluminophosphate particles and inorganic silica binder, J. Sol-Gel Sci. Technol., 2016, 80, 297-305.

5 Y. D. Kim, K. Thu and K. C. Ng, Adsorption characteristics of water vapor on ferroaluminophosphate, Desalination, 2014, 344, 350-356.

6 K. Tsutsumi, K. Mizoe and K. Chubachi, Adsorption characteristics and surface free energy of $\mathrm{AlPO}_{4}-5$, Colloid Polym. Sci., 1999, 277, 83-88.

7 A. Nalaparaju, X. S. Zhao and J. W. Jiang, Molecular understanding for the adsorption of water and alcohols in hydrophilic and hydrophobic zeolitic organic frameworks, J. Phys. Chem. C, 2010, 114, 11542-11550.

8 L. Liu, S. Tan, T. Horikawa, D. D. Do, D. Nicolson and J. Liu, Water adsorption on carbon. A review, Adv. Colloid Interface Sci., 2017, 250, 64-78.

9 S. Furmaniak, P. A. Gauden, A. P. Terzyk and G. Rychlicki, Water adsorption on carbon - Critical review of the most popular analytical approaches, Adv. Colloid Interface Sci., 2008, 137, 82-143.

10 T. Horikawa, D. D. Do and D. Nicolson, Capillary condensation of adsorbates in porous materials, Adv. Colloid Interface Sci., 2011, 169, 40-58.
11 P. J. Branton, P. G. Hall and K. W. S. Sing, Physisorption of alcohols and water vapor by MCM-41, Adsorption, 1995, 1, 77-82.

12 H. Naono, M. Hakuman, T. Tanaka, N. Tamara and K. Nakai, Porous texture and surface character of dehydroxylated and rehydroxylated MCM-41 mesoporous silica. Analysis of adsorption isotherms of nitrogen gas and water vapor, J. Colloid Interface Sci., 2000, 225, 411-420.

13 S. Takahara, S. Kittaka, T. Mori, Y. Kuroda, T. Takamuku and T. Yamagushi, Neutron scattering and dielectric studies on dynamics of methanol and ethanol confinement in MCM-41, J. Phys. Chem. C, 2008, 112, 14385-14393.

14 C. Nguyen, C. G. Sonwane, S. K. Bhatia and D. D. Do, Adsorption of benzene and ethanol on MCM-41 material, Langmuir, 1998, 14, 4950-4952.

15 J. S. Oh, W. G. Shim, J. W. Lee, J. H. Kim, H. Moon and G. Seo, Adsorption equilibrium of water vapor on mesoporous materials, J. Chem. Eng. Data, 2003, 48, 1458-1462.

16 J. W. Lee, W. G. Shim and H. Moon, Adsorption equilibrium and kinetics for capillary condensation of trichloroethylene on MCM-41 and MCM-48, Microporous Mesoporous Mater., 2004, 73, 109-119.

17 J. W. Lee, W. G. Shim, M. S. Yang and H. Moon, Adsorption isotherms of polar and non-polar organic compounds on MCM-48, J. Chem. Eng. Data, 2004, 49, 502-509.

18 W. G. Shim, J. W. Lee and H. Moon, Heterogeneous adsorption characteristics of volatile organic compounds on MCM48, Sep. Sci. Technol., 2006, 41, 3693-3719.

19 I. M. Klotz, F. M. Walker and R. B. Pivan, The binding of organic ions by proteins, J. Am. Chem. Soc., 1946, 68, 1486-1490.

20 I. M. Klotz, Protein interactions with small molecules, Acc. Chem. Res., 1974, 7, 162-168.

21 A. Gürses, C. Doğar, S. Karaca, M. Açikyildiz and R. Bayrak, Production of granular activated carbon from waste and its adsorption characteristics for dye, J. Hazard. Mater., 2006, B131, 254-259.

22 S. Pura and G. Atun, Adsorptive removal of acid blue 113 and tartrazine by fly ash, Sep. Sci. Technol., 2009, 44, 75-101.

23 B. Koubaissy, G. Joly, I. Batonneau-Gener and P. Magnoux, Adsorptive removal of aromatic compounds present in waste water by using dealuminated faujasite zeolites, Ind. Eng. Chem. Res., 2011, 50, 5705-5713.

24 E. H. Ellison and D. Moodley, The hydrophobic effect as a driving force for solute uptake by dealuminated zeolite $\mathrm{Y}$, Microporous Mesoporous Mater., 2007, 99, 251-260.

25 M. M. Dubinin, E. D. Zaverina and V. V. Serpinski, J. Chem. Soc., 1955, 1760-1766.

26 G. Guiochon, S. G. Shirazi and A. Katti, Fundamentals of Preparative and Nonlinear Chromatography, Academic Press, Boston, 1994, p. 74.

27 J. Nowak, K. Gedicke, D. Antos, W. Piątkowski and A. SeidelMorgenstern, Synergistic effects in competitive adsorption of carbohydrates on an ion-exchange resin, J. Chromatogr. A, 2007, 1164, 224-234.

28 A. O. Malakhov and V. V. Volkov, Cooperative multimolecular sorption equation: application to an alcohol-poly(1-trimethylsiyl1-propyne) system, Polym. Sci., Ser. A, 2000, 42, 1120-1126. 
29 S. W. Rutherford, Modeling water adsorption in carbon micropores: Study of water in carbon molecular sieves, Langmuir, 2006, 22, 702-708.

30 A. Chakraborty and B. Sun, An adsorption isotherm equation for multi-types adsorption with thermodynamic correctness, Appl. Therm. Eng., 2014, 72, 190-199.

31 D. D. Do, Adsorption analysis: Equilibria and Kinetics, Imperial College Press, 1998.

32 O. Talu and F. Meunier, Adsorption of associating molecules in micropores and application to water on carbon, AIChE J., 1996, 42, 809-819.

33 A. O. Pedersen, B. Hust, S. Andersen, F. Nielsen and R. Brodersen, Laurate binding to human serum albumin, Eur. J. Biochem., 1986, 154, 545-552.

34 D. D. Do and H. D. Do, A model for water adsorption in activated carbon, Carbon, 2000, 38, 767-773.

35 D. D. Do, S. Junpirom and H. D. Do, A new adsorptiondesorption model for water adsorption in activated carbon, Carbon, 2009, 47, 1466-1473.

36 S. Brunauer, P. H. Emmett and E. Teller, Adsorption of gases in multimolecular layers, J. Am. Chem. Soc., 1938, 60, 309-319.

37 C. A. Ward and J. Wu, Effect of adsorption on the surface tensions of solid-fluid interfaces, J. Phys. Chem. B, 2007, 111, 3685-3694.

38 M. Caurie, The derivation of the GAB adsorption isotherm from the BDDT adsorption theory, Int. J. Food Sci. Technol., 2006, 41, 173-179.

39 R. B. Anderson, Modification of the Brunauer, Emmett and Teller equation, J. Am. Chem. Soc., 1946, 68, 686-691.

40 W. Rudzinski and D. H. Everett. Adsorption of Gases on Heterogeneous Surfaces, Academic Press, San Diego, 1992, pp. 391-392.

41 C. Wu, S. H. Zandavi and C. A. Ward, Prediction of wetting condition from the zeta adsorption isotherm, Phys. Chem. Chem. Phys., 2014, 16, 25564-25572.

42 S. Brunauer, L. S. Deming, W. S. Deming and E. Teller, On a theory of van der Waals adsorption of gases, J. Am. Chem. Soc., 1940, 62, 1723-1732.

43 S. Furmaniak, P. A. Gauden, A. Terzyk, G. Rychlicki, R. P. Wesolowski and P. Kowalcyk, Heterogeneous Do-Do model of water adsorption on carbons, J. Colloid Interface Sci., 2005, 290, 1-13.

44 B. Sun and A. Chakraborty, Thermodynamic formalism of water uptakes on solid porous adsorbents for adsorption cooling applications, Appl. Phys. Lett., 2014, 104, 201901.

45 L. Cossarutto, T. Zimny, J. Kaczmarczyk, T. Siemieniewska, J. Bimer and J. V. Weber, Transport and sorption of water vapor in activated carbons, Carbon, 2001, 39, 2339-2346.

46 C. Nguyen and D. D. Do, The Dubinin-Radushkevich equation and the underlying microscopic adsorption description, Carbon, 2001, 39, 1327-1336.

47 K. W. S. Sing, F. Rouquerol, P. Llewellyn and J. Rouquerol, Assessment of microporosity, in Adsorption by Powders and Porous Solids, ed. F. Rouquerol, J. Rouquerol, K. W. S. Sing, P. Llewellyn and G. Maurin, Academic Press, 2014, pp. 303-320.
48 Ref. 40, Chapter 4.

49 R. Sips, On the structure of catalyst surface II, J. Chem. Phys., 1950, 18, 1024-1026.

50 K. C. Ng, M. Burhan, M. W. Shahzad and A. B. Ismail, A universal isotherm model to capture adsorption uptake and energy distribution of porous heterogeneous surface, Sci. Rep., 2017, 7, 10634.

51 I. Langmuir, The adsorption of gases on plane surfaces of glass, mica, and platinum, J. Am. Chem. Soc., 1918, 40, 1361-1403.

52 R. Alfonso, L. Gales and A. Mendes, Kinetic derivation of common isotherm equations for surface and micropore adsorption, Adsorption, 2016, 22, 963-971.

53 M. Llano-Restrepo and M. Mosquera, Accurate correlation, thermo-chemistry, and structural interpretation of equilibrium adsorption isotherms of water vapor in zeolite $3 \mathrm{~A}$ by means of a general statistical thermodynamic adsorption model, Fluid Phase Equilib., 2009, 283, 73-88.

54 R. Fowler and E. A. Guggenheim, Statistical thermodynamics, Cambridge University Press, 1955, p. 433.

55 T. L. Hill, An Introduction to statistical thermodynamics, Addison Wesley, 1960, p. 134.

56 M. Khalaoui, S. Knani, M. A. Hachida and A. Ben Lamine, New theoretical expressions for the five adsorption type isotherms classified by BET based on statistical thermodynamics, J. Colloid Interface Sci., 2003, 263, 350-356.

57 W. H. Press, B. P. Flannery, S. A. Teukolsky and W. T. Vetterling, Numerical recipes, Cambridge University Press, 1986.

58 I. N. Bronshtein, K. A. Semendyayev and G. Musiol, Handbook of Mathematics, Springer, 2015.

59 The Transforms and Applications Handbook, ed. A. D. Poularikas, CRC-Press, 1996, p. 1022.

60 M. Neitsch, W. Heschel and M. Suckow, Water vapor sorption by activated carbon: a modification of the isotherm model of Do and Do, Carbon, 2001, 39, 1421-1446.

61 S. W. Rutherford, Probing the mechanism of water adsorption in carbon micropores with multi-temperature isotherms and water pre-adsorption experiments, Langmuir, 2006, 22, 9967-9975.

$62 \mathrm{~J}$. Alcañiz-Monge and D. Lozano-Castelló, Assessment of ultra-microporosity on carbon molecular sieves by water adsorption, Adv. Sci. Technol., 2003, 21, 841-848.

63 J. Alcañiz-Monge, A. Linares-Solano and B. Rand, Water adsorption on activated carbons: study of water adsorption in micro- and mesopores, J. Phys. Chem. B, 2001, 105, 7998-8006.

64 N. Naono, M. Hakuman, M. Shimoda, K. Nakai and S. Kondo, Separation of water and ethanol by the adsorption technique: Selective desorption of water from micropores of activated carbon, J. Colloid Interface Sci., 1996, 182, 230-238.

65 L. Sarkisov, A. Centineo and S. Brandani, Molecular simulation and experiments of water adsorption in a high surface area activated carbon. Hysteresis, scanning curves and spatial organization of water clusters, Carbon, 2017, 118, 127-138.

66 K. Lászlo, O. Czakkel, G. Dobos, P. Lodewyckx, C. Rochas and E. Geissler, Water vapor adsorption in highly porous 
carbons as seen by small and wide angle X-ray scattering, Carbon, 2010, 48, 1038-1048.

67 E. O. Wiig and A. J. Juhola, The adsorption of water vapor on activated charcoal, J. Am. Chem. Soc., 1949, 71, 561-568.

68 M. C. Campo, S. Largosse, F. D. Magalhães and A. Mendes, Comparative study between a CMC membrane and a CMS adsorbent. Water vapor adsorption and surface chemistry, J. Membr. Sci., 2010, 346, 26-36.

69 H. Ito, T. Iiyama and S. Ozeki, Kinetics of cluster-mediated filling of water molecules into carbon micropores, J. Phys. Chem. C, 2015, 119, 4118-4124.

70 F. Carrasco-Marin, A. Mueden, T. A. Centeno, F. Stoeckli and C. Moreno-Castilla, Water adsorption on activated carbon with different degrees of oxidation, J. Chem. Soc., Faraday Trans., 1997, 93, 2211-2215.

71 M. G. Plaza, A. S. González, C. Pevida and F. Rubiera, Influence of water vapor on $\mathrm{CO} 2$ adsorption using a biomass-based carbon, Ind. Eng. Chem. Res., 2014, 53, 15488-15499.

72 M. Nakamura, T. Ohba, P. Branton, H. Kanoh and K. Kaneko, Equilibrium-time and pore with dependent hysteresis of water adsorption isotherm on hydrophobic microporous carbon, Carbon, 2010, 48, 305-312.

73 F. Stoeckli, T. Jakubov and A. Lavanchi, Water adsorption in active carbons described by the Dubinin-Astakhov equation, J. Chem. Soc., Faraday Trans., 1994, 90, 783-786.

74 S. Junpirom, C. Tangsathikulchai, M. Tangsathikulchai and Y. Ngernyen, Water adsorption in activated carbons with different burn-offs and its analysis using a cluster model, Korean J. Chem. Eng., 2008, 25, 825-832.

$75 \mathrm{~A} . \mathrm{Li}$, Experimental and theoretical studies on the heat transfer enhancement of adsorbent coated heat exchangers, $\mathrm{PhD}$ thesis, National University of Singapore, 2014, pp. 268-269.

76 N. Sugiura, Further analysis of the data by Akaike's information criterion and the finite correction, Comm. Statist. A., 1978, 7, 13-26.
77 K. P. Burnham and D. D. Anderson, Model selection and multimodal interference: A practical information-theoretic approach, Springer, 2002, p. 63.

78 K. S. W. Sing, Assessment of surface area by gas adsorption, in Adsorption by Powders and Porous Solids, ed. F. Rouquerol, J. Rouquerol, K. S. W. Sing, P. Llewellyn and G. Murin, Elsevier, 2014, ch. 7.

79 U. Buck, C. C. Pradzynski, T. Zeuch, J. M. Dieterich and B. Hartke, A size resolved investigation of large water clusters, Phys. Chem. Chem. Phys., 2014, 16, 6859-6871.

80 M. Nishi, T. Ohkubo, K. Urita, I. Moriguchi and Y. Kuroda, Experimental information on the adsorbed phase of water formed in the inner pore of single-walled carbon nano-tube itself, Langmuir, 2016, 32, 1058-1064.

81 J. Hernández-Rojas, F. Calvo, J. Bretón and J. M. Gomez Llorente, Confinement effects on water clusters inside carbon nano-tubes, J. Phys. Chem. C, 2012, 116, 17019-17028.

82 J. Bahadur, C. I. Contescu, D. K. Rai, N. C. Gallego and Y. B. Melnichenko, Clustering of water molecules in ultramicroporous carbon: In-situ small-angle neutron scattering, Carbon, 2017, 111, 681-688.

83 M. Donohue and G. L. Aranovich, Adsorption hysteresis in porous solids, J. Colloid Interface Sci., 1998, 205, 121-130.

84 A. Wongkoblap and D. D. Do, The effects of curvature and surface heterogeneity on the adsorption of water in finite length carbon nanopores: a computer simulation study, J. Mol. Phys., 2008, 106, 627-641.

85 T. Ohba, S. Yamamoto, T. Kodaira and K. Hata, Changing water affinity from hydrophobic to hydrophilic in hydrophobic channels, Langmuir, 2015, 31, 1058-1063.

86 Structure commission of the International zeolite Association. Database of zeolite structures, 2017, http://europe.izastructure.org/IZA-SC/ftc_table.php. 